\title{
Are the Binding and Degradation of Low Density Lipoprotein Altered in Type 2 (Non-Insulin-Dependent) Diabetes Mellitus?
}

\author{
F. B. Kraemer, Y.-D. I.Chen, R. M.C.Cheung and G. M. Reaven \\ Department of Medicine, Stanford University School of Medicine and Geriatric Research, \\ Education and Clinical Center, Veterans Administration Medical Center, Palo Alto, California, USA
}

Summary. Studies in vitro have shown that glycosylation of low density lipoprotein (LDL) will decrease its ability to bind to its receptor. We have evaluated the possibility that such an event might occur in vivo in diabetes by comparing the binding and degradation by normal fibroblasts and mouse peritoneal macrophages of LDL obtained from normal control subjects and patients with Type 2 (non-insulin-dependent) diabetes mellitus. When compared with control subjects, Type 2 diabetic patients had elevated fasting glucose (increased by $160 \%$ ), haemoglobin $\mathrm{A}_{\mathrm{Ic}}$ (increased by $75 \%$ ), triglyceride (increased by $550 \%$ ), and cholesterol (increased by $48 \%$ ) levels. LDL from Type 2 diabetic patients displayed populations of particles with more heterogeneous hydrated densities than LDL from control subjects, with enrichment in the triglyceride content of the lighter population. ${ }^{125} \mathrm{~J}$-LDL from normal and Type 2 diabetic subjects bound to fibroblasts with similar binding affinities and binding capacities. The kinetics of degradation of LDL from normal and Type 2 diabetic subjects by fibroblasts were also similar. Furthermore, all populations of LDL particles from Type 2 diabetic patients were bound and degraded by normal fibroblasts in identical fashions. In addition, ${ }^{125}$ I-LDL from normal and Type 2 diabetic subjects were not bound or degraded by mouse peritoneal macrophages. It is concluded that the LDL of patients with Type 2 diabetes with moderate hyperglycaemia are not modified sufficiently to alter their normal binding and degradation by human fibroblasts or to cause their uptake by mouse peritoneal macrophages.

Key words: Type 2 diabetes mellitus, low density lipoprotein, lipoprotein binding, lipoprotein degradation, fibroblast, macrophage.
Low density lipoprotein (LDL) catabolism takes place via a highly regulated process of receptor-mediated endocytosis [1]. The initial step in this pathway is the recognition of the B apoprotein of LDL by specific cell surface receptors. Lysine residues of the $B$ apoprotein have been shown to have an important role in this recognition, since chemical modification of this amino acid will lead to a loss of normal binding behaviour [2,3]. Recent studies have demonstrated that incubation of LDL in vitro with glucose can result in glycosylation of lysine residues of LDL, with a resultant decrease in the binding of LDL to receptors on cultured human fibroblasts $[4,5]$ and an increase in the binding of LDL to receptors on rat peritoneal macrophages [6]. These observations raised the possibility that a similar phenomenon could occur in uncontrolled diabetes in vivo. Indeed, Schleicher et al. have recently reported that the level of glycosylated B apoprotein was increased in diabetic patients [7]. In order to evaluate whether LDL from diabetic patients displays any changes in functional behaviour, we have isolated LDL from the plasma of patients with uncontrolled Type 2 (non-insulin-dependent) diabetes, and determined the ability of this LDL to be bound and degraded by cultured normal human fibroblasts and mouse peritoneal macrophages.

\section{Subjects and Methods}

\section{Subjects}

Ten healthy normal control subjects (aged $24-55$ years, mean 46 years) and seven subjects with Type 2 diabetes (aged 45-61 years, mean 56 years) were studied. None of the subjects had evidence of renal or liver disease, or a family history of hyperlipoproteinaemia. All the diabetic subjects were treated with diet alone and/or sulphonylurea therapy at the time of the study. Informed consent was obtained in all cases.

\section{Clinical Studies}

Following an overnight fast, blood was drawn for measurement of glucose [8], insulin [9], haemoglobin $\mathrm{A}_{1 \mathrm{c}}\left(\mathrm{HbA}_{1 \mathrm{c}}\right)$ [10], triglyceride [11] and cholesterol [12] concentrations. On a subsequent occasion, all 


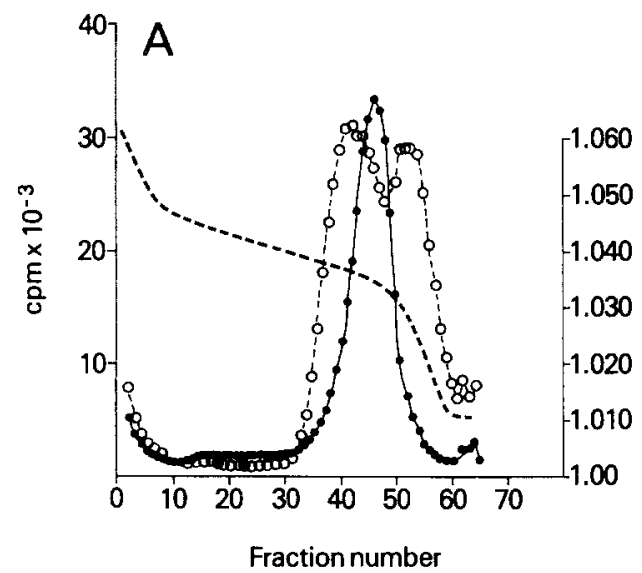

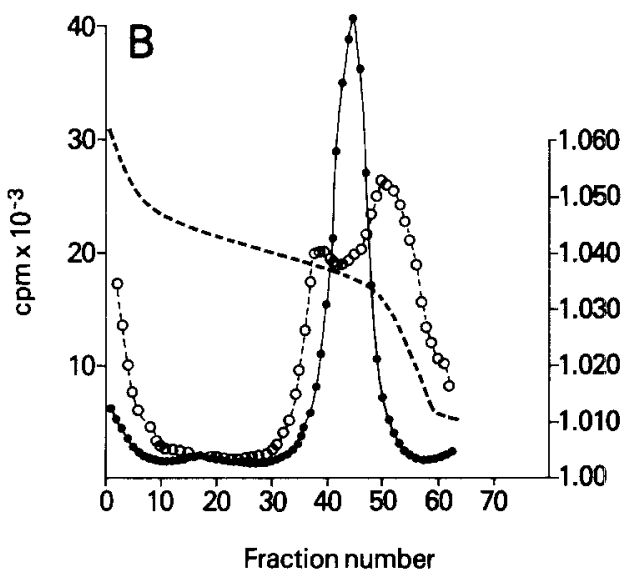

Fig. 1. Distribution of LDL from normal and diabetic subjects on a linear sucrose gradient. Panels $A$ and $B$ represent two individual diabetic subjects. LDL were isolated from normal and diabetic subjects. After radiolabelling normal LDL with ${ }^{131} \mathrm{I}$ and diabetic LDL with ${ }^{125}$ I, the samples were ultracentrifuged on a linear sucrose gradient of $8.02 \%-12.85 \%$. - $\quad$ normal LDL; $\mathrm{O}-\mathrm{O} \mathrm{O} \mathrm{di}$ abetic LDL; -..... : hydrated density
Table 1. Fasting metabolic parameters in control and diabetic subjects.

\begin{tabular}{|c|c|c|c|c|}
\hline & $\begin{array}{l}\text { Glucose } \\
(\mathrm{mmol} / \mathrm{l})\end{array}$ & $\begin{array}{l}\mathrm{HbA}_{\mathrm{Ic}} \\
(\%)\end{array}$ & $\begin{array}{l}\text { Triglyceride } \\
(\mathrm{mmol} / \mathrm{l})\end{array}$ & $\begin{array}{l}\text { Cholesterol } \\
(\mathrm{mmol} / \mathrm{l})\end{array}$ \\
\hline $\begin{array}{l}\text { Control subjects } \\
(n=10) \\
\text { Diabetic subjects }\end{array}$ & $4.76 \pm 0.17$ & $6.8 \pm 0.2$ & $0.88 \pm 0.05$ & $4.46 \pm 0.3$ \\
\hline $\begin{array}{l}(n=7) \\
p\end{array}$ & $\begin{array}{l}12.56 \pm 1.28 \\
<0.001\end{array}$ & $\begin{array}{l}11.7 \pm 0.9 \\
<0.001\end{array}$ & $\begin{array}{l}2.94 \pm 0.59 \\
<0.001\end{array}$ & $\begin{array}{l}6.61 \pm 0.61 \\
<0.01\end{array}$ \\
\hline
\end{tabular}

Results are expressed as mean \pm SEM

subjects were given a formula (containing: 150 protein, 420 carbohydrate and $430 \mathrm{fat} ; \mathrm{g} / \mathrm{kg}$ ) at $12.00 \mathrm{~h}$, and glucose and insulin responses were assessed before and at half-hourly intervals for $3 \mathrm{~h}$ after the meal.

\section{Preparation of Lipoproteins}

Blood was drawn after an overnight fast into tubes containing EDTA acid $(1 \mathrm{mg} / \mathrm{ml})$. LDL $(\mathrm{d}=1.019-1.063)$ were isolated from plasma by ultracentrifugation, using solid $\mathrm{KBr}$ for density adjustment [13]. LDL were acetylated by the addition of acetic anhydride [2]. LDL were iodinated according to MacFarlane [14]. The lipoproteins were extensively dialyzed against $0.15 \mathrm{~mol} / 1 \mathrm{NaCl}, 0.05 \mathrm{~mol} / 1$ Tris- $\mathrm{HCl}(\mathrm{pH} 7.4)$ and sterilized by filtration.

\section{Sucrose Density Gradient}

LDL from normal control subjects were iodinated with ${ }^{131} \mathrm{I}$; LDL from diabetic patients with ${ }^{125} \mathrm{I}$. Aliquots of normal ${ }^{131} \mathrm{I}-\mathrm{LDL}$ and diabetic ${ }^{125} \mathrm{I}-\mathrm{LDL}$ were then mixed and separated on a linear gradient of sucrose $(8.02 \%-12.85 \%)$ by centrifugation at $40000 \mathrm{rev} / \mathrm{min}$ for $18 \mathrm{~h}$ and fractions collected by puncturing the bottom of the tubes. Radioactivity was determined in a two-channel gamma scintillation spectrophotometer and the density of the gradient followed by refractometry.

\section{Cell Cultures}

Human skin fibroblasts were grown from explants from the foreskin of a healthy newborn and maintained in culture as described previously [15]. Experiments were performed on dishes which were approximately $75 \%-95 \%$ confluent and contained $400-450 \mu \mathrm{g}$ of cell protein. Mouse macrophages were harvested from peritoneal exudates of adult, male, Swiss-Webster mice (Simonsen Laboratories,
Gilroy, California, USA) following the injection of $2 \mathrm{ml}$ of thioglycollate medium (Bakte Bennett, Berkeley, California, USA) according to the procedure of Gallily and Feldman [16]. Each dish of adherent macrophages contained $200-250 \mu \mathrm{g}$ of cell protein.

\section{Assays}

Binding was assessed by incubating the cells at $37^{\circ} \mathrm{C}$ in a final volume of $1 \mathrm{ml}$ containing $600 \mu \mathrm{l}$ of media and $5 \%$ lipoprotein deficient serum, and various concentrations of ${ }^{125} \mathrm{I}-\mathrm{LDL}(5-100 \mu \mathrm{g}$ LDL protein). Non-specific binding was assessed by the addition of a 10-100fold excess of radio-inert LDL to parallel dishes. After incubation $(2 \mathrm{~h}$ for fibroblasts; $24 \mathrm{~h}$ for macrophages), the cells were placed on ice, the medium removed, and the dishes then washed four times with $1 \mathrm{ml}$ of $0.15 \mathrm{~mol} / 1 \mathrm{NaCl}, 0.05 \mathrm{~mol} / 1$ Tris $\mathrm{HCl}(\mathrm{pH}$ 7.4), $5 \mathrm{mmol} / \mathrm{I} \mathrm{CaCl}_{2}$, and $2 \mathrm{mg} / \mathrm{ml}$ of bovine serum albumin, followed by one wash with $2 \mathrm{ml}$ of the same buffer without bovine serum albumin. The cells were dissolved in $1 \mathrm{ml}$ of $0.5 \mathrm{~N} \mathrm{NaOH}$, and their radioactivity determined in a gamma scintillation spectrophotometer. An aliquot of the cells was taken for determination of cellular protein content [17]. Although total binding reflects both the ${ }^{125} \mathrm{I}$-LDL that is surface bound, as well as that internalized, we have expressed the results as ng LDL protein bound/mg cell protein. The degradation of ${ }^{125}$ I-LDL by the cells was determined by assessing the amount of radioactivity in the medium that is soluble after trichloroacetic acid $(10 \% \mathrm{w} / \mathrm{v}$ final concentration) precipitation, and after extraction of free iodine with chloroform [15]. The results are expressed as ng LDL protein degraded $/ \mathrm{mg}$ cell protein.

\section{Results}

The results in Table 1 demonstrate that the patients with Type 2 diabetes had marked fasting hyperglycaemia, associated with a $75 \%$ increase in their $\mathrm{HbA}_{1 \mathrm{c}}$ levels. Postprandial excursions of plasma glucose were as high as $20-25 \mathrm{mmol} / \mathrm{l}$, emphasizing the severity of diabetes in this problem. The insulin responses during feeding were not significantly different between diabetic and control subjects. Finally, patients with Type 2 diabetes had a sixfold higher value of fasting plasma triglyceride concentrations with a $50 \%$ elevation in their fasting serum cholesterol levels when compared with control subject (Table 1).

When LDL were isolated using conventional density adjusted ultracentrifugation methods, two popula- 

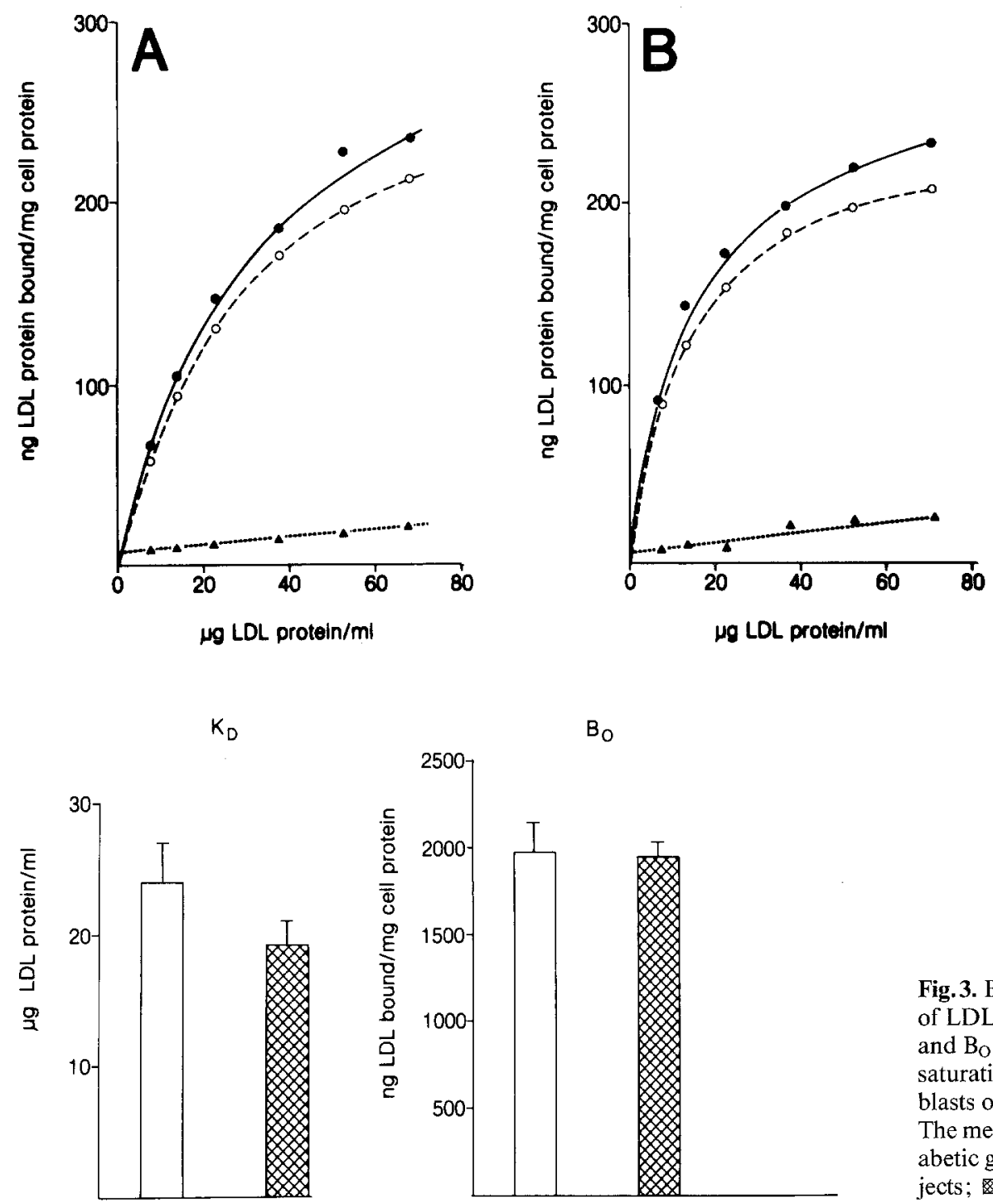

$\mathrm{B}_{\mathrm{O}}$

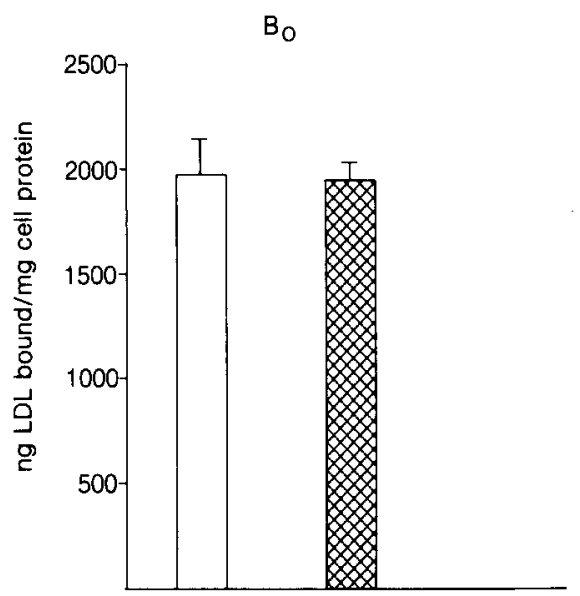

Fig. 2. Saturation curves of binding of LDL from a normal $(A)$ and a diabetic $(B)$ subject to normal human fibroblasts. The indicated concentrations of ${ }^{125}$ I-LDL were incubated with monolayers of human fibroblasts at $37^{\circ} \mathrm{C}$ for $2 \mathrm{~h}$. Parallel dishes contained $2.5 \mathrm{mg} / \mathrm{ml}$ of radio-inert LDL. $\longrightarrow$ : total binding; $\mathbf{\Delta} \ldots \ldots . \Delta$ : non-specific binding; $\mathrm{O}---\mathrm{O}$ : specific binding
Fig. 3. Binding affinity $\left(\mathrm{K}_{\mathrm{D}}\right)$ and binding capacity $\left(\mathrm{B}_{\mathrm{O}}\right)$ of LDL from normal control and diabetic subjects. $K_{D}$ and $B_{O}$ were derived from Scatchard plots made from saturation curves of binding to normal human fibroblasts of ${ }^{125}$ I-LDL isolated from individual subjects. The mean \pm SEM of $K_{D}$ and $B_{O}$ for the control and diabetic groups were then calculated. $\square$ : control subjects; diabetic patients tions of LDL were noted in several patients with Type 2 diabetes. This was in contrast to the apparent homogeneity of LDL from normal subjects. When the isolated LDL were differentially radiolabelled and separated in a linear gradient of sucrose, the differences between the LDL from normal and diabetic subjects became clearer (Fig. 1). The normal LDL displayed a homogeneous pattern, with a mean hydrated density of 1.035 . In contrast, LDL from diabetic patients were more heterogeneous, with peaks occurring at mean hydrated densities of 1.033 and 1.0375 . A comparison of the lipid compositions of normal LDL and the two populations of diabetic LDL is shown in Table 2. The diabetic LDL of greater density (peak 1) have a similar triglyceride/protein ratio and a slightly lower cholesterol/protein ratio when compared with controls; while the lighter diabetic LDL (peak 2) are enriched in triglyceride content with comparable or small increases in cholesterol/protein ratios.

The binding of LDL to cultured human fibroblasts is illustrated in Figures 2 and 3. Figure 2 displays typical curves of the binding of LDL from a normal and a diabetic subject when incubated with normal human fibroblasts in culture. LDL from normal and diabetic subjects showed high affinity, saturable binding of a similar degree. The binding results of LDL obtained from all subjects were analyzed by Scatchard plots (Fig.3). It is apparent that there are no differences between either the apparent binding affinities or capacities of LDL isolated from normal and diabetic subjects.

In addition, cultured fibroblasts degraded LDL obtained from normal and diabetic subjects to the same extent (Fig. 4). The results of the degradation studies of all subjects were analyzed by Lineweaver-Burk plots, and there were no differences between either the apparent $\mathrm{K}_{\mathrm{m}}$ or $\mathrm{V}_{\max }$ for degradation of LDL obtained from normal and diabetic subjects (Fig. 5).

In order to test the possibility that the different peaks of LDL identified in these patients might behave differently, studies were carried out comparing the two different classes of LDL seen in the plasma of patients with Type 2 diabetes. These results indicated that the 

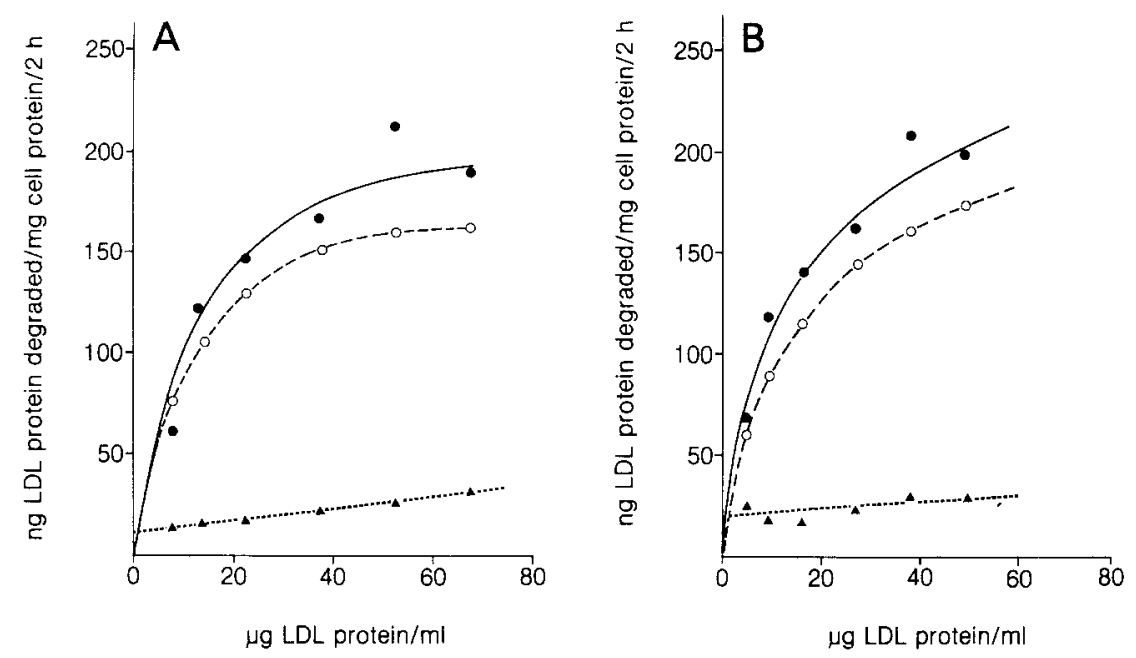

Fig.4. Saturation curves of degradation of LDL from a normal $(A)$ and a diabetic subject $(B)$ by normal human fibroblasts. The indicated concentrations of ${ }^{125}$ I-LDL were incubated with monolayers of human fibroblasts at $37^{\circ} \mathrm{C}$ for $2 \mathrm{~h}$. Parallel dishes contained $2.5 \mathrm{mg} / \mathrm{ml}$ of radio-inert LDL. Media were assayed for trichloroacetic acid soluble, non-free iodine, degradative products. $\longrightarrow$ : total degradation; $\boldsymbol{\Delta} \cdots \cdots \cdot \mathbf{\Delta}:$ non-specific degradation; O-..-O : specific degradation
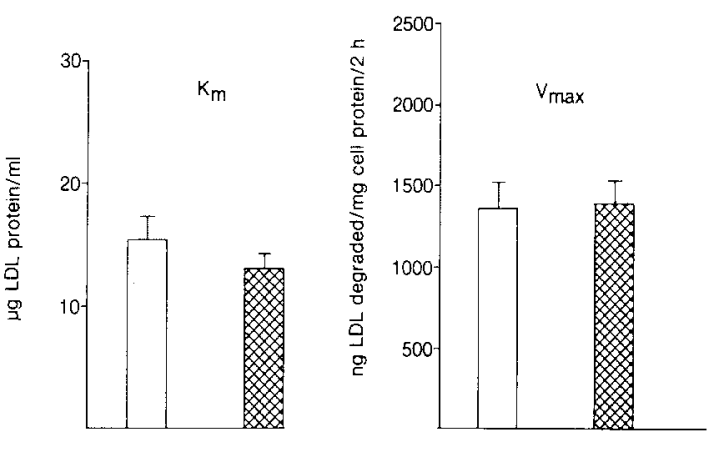

Fig.5. Kinetics of degradation of LDL from normal control and diabetic subjects. Apparent $K_{m}$ and $V_{\max }$ were derived from LineweaverBurk plots made from saturation curves of degradation by normal human fibroblasts of ${ }^{125} \mathrm{I}$-LDL isolated from individual subjects. The mean \pm SEM of apparent $K_{m}$ and $V_{\max }$ for the control and diabetic groups were then calculated: $\square$ : control subjects: diabetic subjects two different forms of LDL interacted in identical fashion with LDL receptors of cultured fibroblasts (data not shown).

Although LDL isolated from patients with Type 2 diabetes interacted normally with the LDL receptor on fibroblasts, it was possible that these LDL were modified in a manner that now would permit them to be processed by an alternate or 'scavenger' pathway, as proposed by Goldstein et al. [18, 19]. This possibility was evaluated by examining the binding and degradation of LDL by macrophages isolated from the mouse peritoneum. As reported previously [19], chemical modification of LDL by acetylation resulted in a particle which was avidly taken up and degraded by a high affinity saturable process by mouse peritoneal macrophages (Fig. 6). In contrast, LDL isolated from patients with Type 2 diabetes failed to display any saturable binding

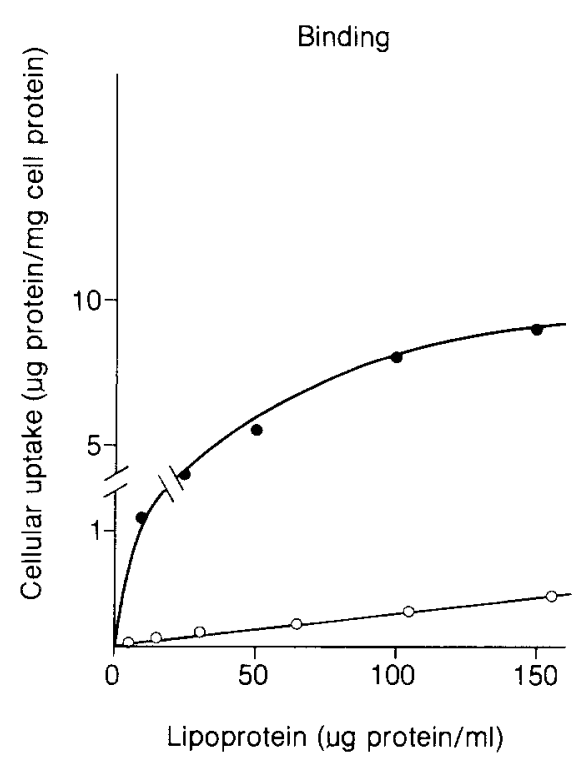

Lipoprotein (ug protein/ml)

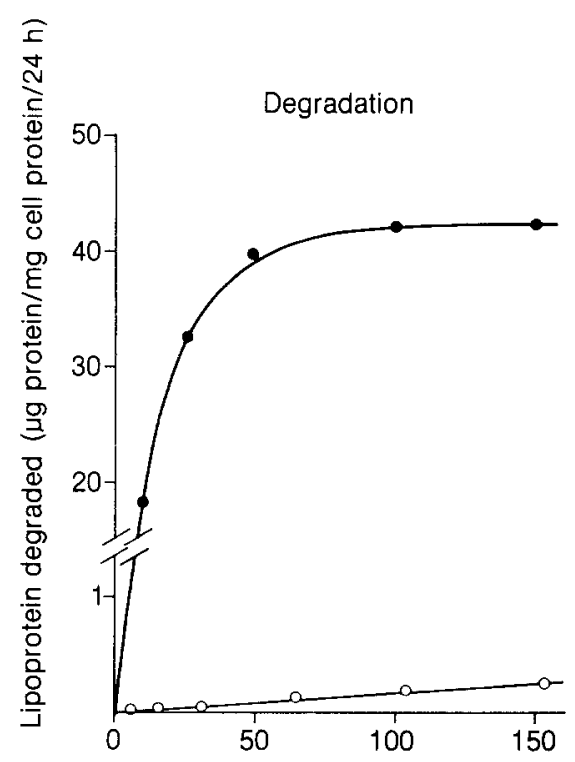

Lipoprotein ( $\mu \mathrm{g}$ protein/ml)
Fig. 6. Saturation curves of binding and degradation of acetylated LDL and LDL from a diabetic subject $(\mathrm{O}-\mathrm{O})$ by mouse peritoneal macrophages. The indicated concentrations of ${ }^{125}$ I-lipoproteins were incubated with monolayers of mouse peritoneal macrophages at $37^{\circ} \mathrm{C}$ for $24 \mathrm{~h}$. The curves represent the specific binding and degradation after correction for the amount of lipoproteins bound and degraded in the presence of $2 \mathrm{mg} / \mathrm{ml}$ of radio-inert lipoproteins 
and degradation by the mouse macrophages. In addition, LDL from normal controls behaved identically (not shown). Therefore, LDL from patients with Type 2 diabetes interacted normally with receptors on both fibroblasts and cells of the scavenger pathway.

\section{Discussion}

The results of these studies have indicated that LDL isolated from patients with Type 2 diabetes are bound and degraded normally by both human fibroblasts and mouse peritoneal macrophages. Thus, we could find no evidence that hyperglycaemia in vivo led to a change in the functional behaviour of isolated LDL. These findings are in contrast with recent reports in which glycosylation in vitro markedly altered the binding of LDL to cultured human fibroblasts [5] and rat peritoneal macrophages [6]. The fact that glycosylation in vitro altered the binding and degradation of LDL is not unexpected in light of the current knowledge. It is known that the recognition site of LDL for its receptor involves arginine and lysine residues. By blocking the amino groups of arginine with ${ }^{1,2}$ cyclohexanedione, or the $\varepsilon$-amino groups of lysine by reductive methylation in vitro, the high affinity binding and subsequent degradation can be abolished [3, 20]. Hyperglycaemia has been shown to lead to abnormal glycosylation of haemoglobin, as well as other serum proteins, by forming a Schiff base with the $\varepsilon$-amino groups of lysine and subsequently undergoing the non-enzymatic Amadori rearrangement to form a more stable compound [21]. Recently, LDL from diabetic patients has been reported to be similarly glycosylated [7]. If the lysine residues of the apoprotein of LDL were glycosylated to a significant degree, one might expect to observe an alteration in the manner with which LDL interacts with its receptor. Therefore, it is not immediately obvious why we could not document any change in the binding or degradation of LDL isolated from patients with Type 2 diabetes.

One possible explanation for the disparity of results in vitro and in vivo relates to the condition of the two kinds of studies. For example, the concentrations of glucose utilized in studies in vitro (up to $100 \mathrm{mmol} / \mathrm{l}$ ) were much higher than those observed in our patients, and the incubations were maintained for a period of time greater than the normal half-life of LDL in plasma. Therefore, the fact that LDL isolated from patients with Type 2 diabetes did not express the same abnormality should not be too surprising. Although our results do not prove that glycosylation of LDL could never lead to a lipoprotein which demonstrated abnormal binding and degradation, the metabolic characteristics of our patient population suggest that this phenomenon must be limited to patients with extremely severe hyperglycaemia. The diabetes in our patients was clearly under poor control - they had significant fasting hyperglycaemia, $\mathrm{HbA}_{\mathrm{Ic}}$ levels were aproximately twice-normal, and post-prandial plasma glucose concentrations were as high as $25 \mathrm{mmol} / 1$. Unfortunately, our data provide no insight as to the level of hyperglycaemia that might be necessary to achieve the degree of glycosylation required to lead to abnormal LDL binding, but preliminary observations by Lopes-Virella et al. [22] lend support to the concept that subtle changes in LDL catabolism may exist in diabetes. They stated that the ability of fibroblasts to degrade LDL isolated from poorly controlled patients with Type 1 (insulin-dependent) diabetes was decreased, and that improved metabolic control remedied this defect. However, no changes were noted in LDL binding, and the information available does not permit a detailed comparison with our results. Nonetheless, their observations are consistent with the possibility that the LDL of at least some patients with diabetes might be altered (glycosylated) enough to lead to abnormal catabolism.

A second possible reason for the disparity between binding in vitro and in vivo relates to the catabolic rate of LDL in vivo. Thus, it is possible that a subset of LDL particles are generated in vivo which would demonstrate abnormal binding and/or degradation, but these particles may be cleared so rapidly in vivo that their isolation from plasma is impossible. Therefore, it is imperative that our results not be over-interpreted. All we can legitimately conclude is that LDL isolated from patients with a severe form of Type 2 diabetes interact normally with the LDL receptor on cultured human fibroblasts and do not interact abnormally with mouse peritoneal macrophages.

Finally, the observation that the hydrated densities of LDL from patients with Type 2 diabetes were more heterogeneous is worthy of some comment. Neither the origin nor the catabolic fate of these particles is apparent. For example, do they arise during the process of conversion of very low density lipoproteins to LDL, or subsequent to the formation of LDL? Do they only interact with the normal LDL receptor, or can they also be catabolized by alternative pathways? Answers to these questions are issues which we are currently addressing.

Acknowledgements. We would like to thank M.Ruth for excellent technical assistance. This work was supported in parts by grants from the National Institutes of Health HL-08506, and the Research Services of the Veterans Administration.

\section{References}

1. Goldstein JL, Brown MS (1977) The low density lipoprotein pathway and its relation to atherosclerosis. Ann Rev Biochem 46: 897-930

2. Basu SK, Goldstein JL, Anderson RGW, Brown MS (1976) Degradation of cationized low density lipoprotein and regulation of cholesterol metabolism in homozygous familial hypercholesterolemia fibroblasts. Proc Natl Acad Sci USA 73: 3178-3182

3. Weisberger KH, Innerarity TL, Mahley RW (1976) Role of lysine residues of plasma lipoproteins in high affinity binding to cell surface receptors on human fibroblasts. J Biol Chem 253: 9053-9062 
4. Gonen B, Jacobsen D, Farrar P, Schonfeld G (1981) In vitro glycosylation of low density and high density lipoproteins. Diabetes 30: $875-878$

5. Witztum JL, Branks MJ, Steinberg D (1981) Nonenzymatic glycosylation of low density lipoproteins (LDL) interferes with its high affinity receptor uptake by fibroblasts. Clin Res 29: 61 (Abstract)

6. Kim HJ, Kurup IV (1980) Increased catabolism of glycosylated low density lipoprotein by rat peritoneal macrophage. Diabetes 29 (Suppl 2): 2 (Abstract)

7. Schleicher E, Deufel T, Wieland OH (1981) Non-enzymatic glycosylation of human serum lipoproteins. Elevated $\varepsilon$-lysine glycosylated low density lipoproteins in diabetic patients. FEBS Lett 129: $1-4$

8. Kadish AH, Little RL, Steinberg JC (1968) A new and rapid method for determination of glucose by measurement of rate of oxygen consumption. Clin Chem 14: 116-131

9. Desbuquois B, Aurbach GD (1971) Use of polyethylene glycol to separate free and antibody bound peptide hormones in radioimmunoassays. J Clin Endocrinol Metab 33: 732-738

10. Schwartz HC, King KC, Schwartz AL, Edmunds D, Schwartz R (1976) Effects of pregnancy on hemoglobin $A_{I c}$ in normal, gestational diabetic, and diabetic women. Diabetes 25: 1118-1122

11. Wahlfeld AW (1974) Triglyceride determination after enzymatic hydrolysis. In: Bergmeyer HV (ed) Methods of enzymatic analysis, 2nd edn. Academic Press, New York, pp 1831-1835

12. Abel LL, Levy BB, Brodie BB, Kendall FE (1952) A simplified method for the estimation of total cholesterol in serum and demonstration of its specificity. J Biol Chem 195: 357-366

13. Havel RJ, Eder HA, Bragdon JH (1955) The distribution and chemical composition of ultracentrifugally separated lipoproteins in human serum. J Clin Invest 34: 1345-1353

14. MacFarlane AS (1958) Efficient trace-labelling of proteins with iodine. Nature 182: 53

15. Goldstein JL, Brown MS (1974) Binding and degradation of low density lipoproteins by cultured human fibroblasts. Comparison of cells from a normal subject and from a patient with homozygous familial hypercholesterolemia. J Biol Chem 249: 5153-5162

16. Gallily R, Feldman M (1967) The role of macrophages in the induction of antibody in X-irradiated animals. Immunology 12 : 197-205

17. Markwell MAK, Haas SM, Bieber LL, Tolbert NE (1978) A modification of the Lowry procedure to simplify protein determination in membrane and lipoprotein samples. Anal Biochem 87:206-210

18. Goldstein JL, Brown MS (1977) Atherosclerosis: the low density lipoprotein receptor hypothesis. Metabolism 26: 1257-1275

19. Goldstein JL, Ho YK, Basu SK, Brown MS (1979) Binding site on macrophage that mediates uptake and degradation of acetylated low density lipoprotein, producing massive cholesterol deposition. Proc Natl Acad Sci USA 76: 333-337

20. Mahley RW, Innerarity TL, Pitas RE, Weisgraber HK, Brown JH, Gross E (1977) Inhibition of lipoprotein binding to cell surface receptors of fibroblasts following selective modification of arginyl residues in arginine-rich and B apoproteins. J Biol Chem 252: 7279-7287

21. Bunn AF, Gabbay HK, Gallop PM (1978) The glycosylation of hemoglobin: relevance to diabetes mellitus. Science 200:21-27

22. Lopes-Virella MF, Sherer G, Lees AM, Wohlfmann H, Mayfield R, Sagel J, LeRoy C, Colwell JA (1981) Uptake and degradation by human fibroblasts of LDL isolated from patients. Changes with metabolic control. Clin Res 29: 425 A (Abstract)

Received: 10 August 1981

and in revised form: 22 February 1982

Gerald M. Reaven, M.D.

Veterans Administration Medical Center (182 B)

3801 Miranda Avenue

Palo Alto

Ca 94304, USA 